\title{
Performance-based ship management contracts using the Shipping KPI standard
}

\author{
Agathe Rialland • Dag Atle Nesheim • \\ Jan Arthur Norbeck • Ørnulf Jan Rødseth
}

Received: 13 March 2013 / Accepted: 28 January 2014 / Published online: 11 February 2014

(C) World Maritime University 2014

\begin{abstract}
An important benefit of performance-based contracts is a better risk and profit-sharing mechanism and by that a means to overcome the "split incentive" problem in current shipping contracts. "Split incentive" means that the risk or cost of implementing beneficial measures does not fall on the same party that gets the benefits. However, performance-based contracts do not come without challenges. These are related to defining commonly agreed performance measurements and an incentive scheme that can counteract problems like allocative efficiency and information asymmetry. This paper gives an example of how these challenges can be addressed by using the Shipping KPI standard. The purpose of the paper is to show how a standard set of key performance indicator definitions and corresponding benchmark values can greatly simplify the design of a performance-based contracts scheme by providing well-defined references for both owner and manager. This is done by creating a bonus and penalty scheme where the payment is related to a single variable (budget performance), while a number of quality indicators control whether a bonus will be paid at all. The paper will discuss this principle in relationship to problems identified in literature on performancebased contracting and ship management and provide an overview of possible strengths and weaknesses.
\end{abstract}

Keywords Performance-based contract · Ship management · Shipping KPI · KPI · Management contract

\section{Introduction}

Shipping operations are facing a number of challenges. These are related to, e.g., increasing costs, such as higher fuel and crew expenses, societal issues, such as ever stricter emission regimes and a stronger focus on energy efficiency, and all these in a

A. Rialland · D. A. Nesheim · J. A. Norbeck $• \varnothing$. J. Rødseth $(\bowtie)$

Norsk Marinteknisk Forskningsinstitutt AS (MARINTEK), POB 4125 Valentinlyst, NO-7450 Trondheim, Norway

e-mail: OrnulfJan.Rodseth@marintek.sintef.no 
market characterized by highly irregular market cycles and intense international competition.

Over many years, shipping has dealt with similar challenges by developing an efficient framework of regulatory and contractual relationships between the parties. However, as the challenges continue to grow and new technologies such as automatic identification systems and proliferating satellite communication provide a strong technology push, there is a definitive need and potential to look for new types and more modern contractual relationships between the parties. The performance-based contract $(\mathrm{PbC})$ and its applicability by introducing a standard set of key performance indicators (KPIs) will be examined in this paper.

There are several issues that complicate the use of $\mathrm{PbC}$, and at the heart of these is arguably the availability of reliable information. The Shipping KPI standard (Shipping KPI 2012) provides a standard key performance indicator system and benchmarking facilities for participating ship management companies as well as facilitates communication of own performance to other parties by providing industry benchmarks. Although the Shipping KPI standard also faces some challenges such as data reliability (see Section 5.1), it is an interesting proposal as a neutral information source for use in $\mathrm{PbC}$.

In the EU-supported Flagship project (2011), a number of scenarios for future shipping operations were developed, and a clear trend also here was the need for more efficient cooperation between the different parties. The roles of KPIs and $\mathrm{PbC}$ were among the issues discussed and which were expected to make an impact in the future. This lead to the idea of testing out a simple concept of $\mathrm{PbC}$ in ship management based on the performance measurements developed by Shipping KPI (Norbeck et al. 2011). This paper revisits the $\mathrm{PbC}$ approach used in that study and puts it into a more extensive framework where benefits and problems related to the described approach are identified and discussed.

\section{Method}

The research question posed by this paper is the following: The Shipping KPI standard introduces a standard way to measure ship operation performance and a database that makes it possible to provide benchmark values for the KPIs. How can this be used to develop a simple and robust $\mathrm{PbC}$ scheme between ship owners and managers?

To answer this question, this paper reviews a proposed method from Norbeck et al. (2011). It demonstrates how clauses in the SHIPMAN ship management contract (BIMCO 2009) can be mapped to performance indicators in the Shipping KPI system and then used to propose a PbC extension to SHIPMAN. By using real life KPI values from the Shipping KPI database populated from 200 ships over a full year, it also shows how performance criteria in the $\mathrm{PbC}$ contract can be determined empirically. Finally, the resulting contract proposal is tested against some sample cases in the Shipping KPI database to see how these cases would perform in a real-world setting.

The paper is based on the same data sample and results as was used in the original study. The contribution of this paper is to provide a better understanding of the methodology, including strengths and weaknesses based on a qualitative assessment and more extensive literature studies. The assessment and literature studies include an overview of the Shipping KPI standard in terms of suitability for $\mathrm{PbC}$ as well as more 
general problems related to $\mathrm{PbC}$ in shipping, in particular, what incentive schemes are used and problems that may occur.

Section 3 reviews ship management and ship management contracts and identifies what issues are important in the relationship between ship owners and managers. Section 4 reviews performance-based contracting and some important problems that have been identified related to its use. Section 5 gives an overview of the Shipping KPI standard. Section 6 explains the $\mathrm{PbC}$ method developed in the Flagship project and discusses how that may perform in light of the issues identified in the literature study. A discussion, summary, and conclusion can be found in Sections 7 and 8 .

\section{Owner-manager relationships and contracts}

When a ship owner has contracted a ship manager to operate the ship, different functions are outsourced. This may include crewing, technical operations, and other services. A commonly used contract format is the BIMCO's SHIPMAN contract (BIMCO 2009). This contract is a typical "costs plus fixed price" type (CPFF in Fig. 2). This means that the contract has no incentive component: The manager gets paid for the specific services that are needed and gets all external costs refunded.

According to Mitroussi (2004), ship owners are in general somewhat reluctant to hire in third party ship managers. This is contrary to a number of market mechanisms that should encourage this type of outsourcing, including the increasing complexity in shipping and corresponding need for specialized expertise and tools as well as economics of scale. The reasons for the owners' skepticism varies, but the main issues are reported to be sufficient in internal expertise, the need to be in contact with the market oneself, and the desire to be in control of the ship operations oneself. Another factor, reported by $49 \%$ of the respondents, is a general lack of confidence in ship managers. Fifty-one owners responded in this investigation.

On the other hand, the top four reasons for using ship management is reported to be expertise $(73 \%)$, access to crew (60\%), flexibility (60\%), and economies of scale $(53.3 \%)$. With a total of 15 respondents on this part, the statistical significance may be somewhat limited, but it can be argued that the ship owners seem to look for efficient and competent management companies that offer a reasonable price, but that about $50 \%$ of the owners do not trust the managers to deliver this. Price alone is not a decisive factor but is important as soon as the quality attributes are ascertained. A similar picture emerges in the study by Panayides and Cullinane (2002). The study received answers from 36 ship owners and found that when owners select management companies, they foremost emphasize quality of services (technical ability, qualifications, experience, and specialization), then reputation (reputation and recommendations) and in third place, price.

From these studies, there seem to be a certain lack of trust between ship owners and management companies. This may make the use of less prescriptive contracts than SHIPMAN difficult, unless reliable and transparent performance measures can be established. Shipping KPI can play a role here, but the lack of trust can also be a problem in the Shipping KPI standard itself. This issue will be returned to in Section 5.

The relatively lower emphasis on management cost by the owners may be explained by the management fee being a relatively small part of the total operational cost. One 
example from a European-operated handymax bulker was presented by Norbeck et al. (2011) and is repeated in Fig. 1. Here, the management fee is only $10 \%$ of the total daily operational budget of US\$4,100.

For the owner, the operational cost is only a part of the cash flow, where additional items such as capital costs, insurance, and own operational costs have to be added to the total expenses. For operations, the charter hire is the main income and this has varied from less than US\$10,000 to around US $\$ 60,000$ per day for a handymax over the last 10 years. Thus, the relative size of the operating budget compared to the total costs will be a highly variable number.

\section{Performance-based contracts and some identified problems}

\subsection{Different types of performance-based contracts}

Contracts are "formal mechanisms of management control" (Homburg and Stebel 2009). They consist of a written set of agreed-upon rules used to monitor a transaction in a formal manner. The contract can be defined as an agreement between two parties where the principal pays the agent a certain fee to provide certain services.

Contract theory started to evolve around the start of the twentieth century and evolved through uncertainty in 1950 with asymmetric relationships, and the start of incentive contracting research emerging around 1960 (Hooper 2008). Incentive-based contracts are contracts under which the agent's benefit depends on the principal's benefit as opposed to respectively fixed price contracts (FFP) where risks are solely on the agent's side, and time and material contracts ( $\mathrm{T}$ and $\mathrm{M}$ ) where risks are solely on the principal's side. Incentive-based contracts enable the sharing of risks and rewards. Performance-based contracts represent a subset of incentive-based contracts in which the reward and penalty scheme is defined based on the performance delivered (McCall 1970).

Based on the classifications from Al-Subhi Al-Harbi (1998), one can draw a map of different contract types ranging from the FFP type, via incentive-based to time and material type contracts (Fig. 2). The three types of incentive-based contracts shown here (shaded) are the following:

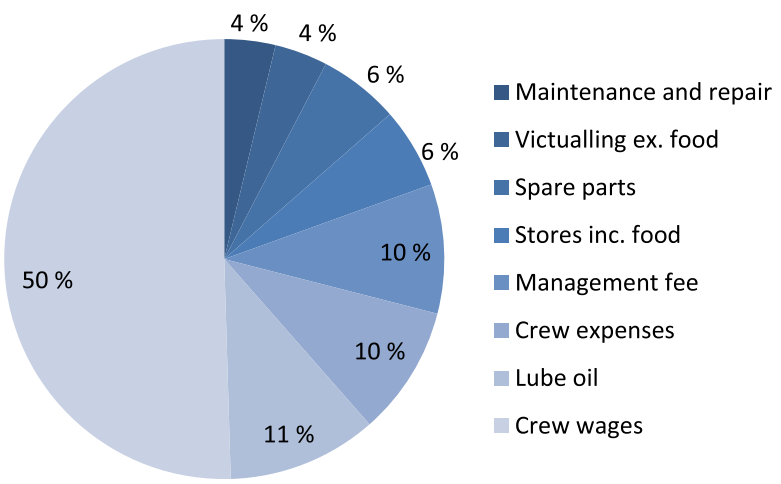

Fig. 1 Daily operational expenses (e.g., dry docking and insurance) 


\begin{tabular}{|c|c|c|c|c|c|c|}
\hline \multicolumn{1}{|c}{ Agent's risk } & High \\
\hline T\&M & $\begin{array}{c}\text { CPPC } \\
\text { Cost plus } \\
\text { Time and } \\
\text { material } \\
\text { percentage } \\
\text { of cost }\end{array}$ & $\begin{array}{c}\text { Cost plus } \\
\text { fixed fee }\end{array}$ & $\begin{array}{c}\text { CPIF } \\
\text { Cost plus } \\
\text { incentive } \\
\text { fee }\end{array}$ & CPAF & FPI & FFP \\
award fee \\
\cline { 2 - 5 }
\end{tabular}

Fig. 2 Contract type and associated risk (adapted from Al-Subhi Al-Harbi 1998)

- Fixed price incentive (FPI), a contract under which the target profit depends on both the targeted costs and an agreed-upon sharing proportion. The savings realized are shared based on an agreed ratio (McCall 1970; Al-Subhi Al-Harbi 1998).

- Cost-plus-award-fee (CPAF), where the agent is paid all reasonable costs, plus a (subjective) award based on the agent's work performance, determined, e.g., by an award committee. This type of contract is more subjective than CPIF, and therefore more flexible, but is relatively more costly in administration.

- Cost-plus-incentive-fee (CPIF), a contract under which a specific rate of profit for a given level of performance is agreed, together with an incentive payment for higher levels of performance.

Commonly used ship management contracts such as the BIMCO's standard SHIPMAN contract can be placed in the figure as a CPFF type contract.

All principal-agent relationships and contract types are subject to a number of problems that have been discussed extensively in the literature. In the following subsections, we discuss three general problems that are of particular interest in performance-based contracts.

\subsection{Allocative efficiency}

Allocative efficiency (Michael 1957) means that in a multitask contract, the agent will tend to put more effort into more observable or better paid tasks. Effort substitution, effort distortion, and manipulation of measures are typical cases of this "multiple tasks moral hazard" problem (Hooper 2008; Zhao 2008; Fearnley et al. 2004, Holmstrom and Milgrom, 1991). They are explained by the agent's tendency to allocate efforts in order to maximize own margins or in a way that "makes them look good" (Woods 2012), but not necessarily in line with the principal's objectives. These problems are well known and widely covered in the literature on performance-based contracts. Unfortunately, no suggestions exists for a "standard" incentive schemes to overcome this problem. This is to be expected given the complexity and large number of factors and trade-offs influencing the design of payment models (Hooper 2008).

One suggestion is to establish several bonuses based on distinct measures in order to rebalance the incentives (Gibbs et al. 2004). However, this may also increase the information asymmetry problem and making the bonus and penalty calculation more complex. A similar suggestion is to use nonfinancial measures to complement the financially based level of compensation. This can better reflect overall performance, as 
suggested by Feltham and Xie (1994). This is close to the principle employed in this study. The idea of budget fulfillment for calculation of bonus together with quality check for appropriation of bonus has also been discussed in more detail in an empirical study on ship management contracts (Hollebrands 2011).

\subsection{Information asymmetry}

Information asymmetry means that the principal and agent have access to different information and can use this to skew the relationship between the two. Information asymmetry is a fundamental problem in principal-agent relationships and can create problem of adverse selection or moral hazard. Adverse selection happens when a principal enters into a contract with an agent on false premises, and moral hazard is the tendency of an agent to take shortcuts when the principal does not have easily available means to detect it. When choosing an incentive scheme, principals face the challenge of defining performance criteria and targets that can neutralize the negative consequences of information asymmetry.

A correct set of precise performance measures is the key, if one wants to elude the "folly of rewarding A, while hoping for B" (Kerr 1975). In line with this, Zhao (2008) recommends using direct results indicators, which will help to ensure observability of tasks and results. Also, a unique compensation is recommended by several studies, either calculated on quantity results (Zhao 2008; Rajan and Reichelstein 2009) or on quality results (Olmos and Martinez 2010). Unique and direct quantity results are used in this study.

\subsection{Contract complexity}

The anticipation of time and resource necessary to implement and monitor performance-based contracts - define incentive scheme, design contract format, select parameters, set target values, follow-up and adapt to exceptions, and handle afterdelivery negotiation - can be quite dissuasive. More specifically, intense communication during performance analysis and the interpretation of the contract terms and definitions are two main sources of high monitoring costs which have been reported by Hollebrands (2011). This will at least in part be addressed by the use of the Shipping KPI standard which is a generally agreed-upon set of performance measures defined by the managers themselves.

\section{The Shipping KPI standard}

\subsection{Overview of Shipping KPI}

The Shipping KPI standard was launched for general use in 2010 by InterManager and later revised in 2012. It is now a de facto standard set of key performance indicators for ship operations and ship management. The Shipping KPI database contains data from more than 2,000 ships as of July 2013 and is growing steadily. Shipping KPI is an interesting set of measurement points for a ship management $\mathrm{PbC}$ as they are standardized and well understood. A growing number of users also make it possible to 
provide statistically significant benchmark values to be used as reference points in the contracts.

The Shipping KPI standard consists of eight high-level shipping performance indexes (SPI), each representing a central performance area for ship operations. The SPIs and their general description are listed in Table 1. Each SPI is aggregated from a number of KPIs which again are calculated from low-level performance indicators (PI). The number of PIs and KPIs used in each SPI is listed in the table. Most PIs are only used to construct one specific KPI (sum of 78 occurrences versus 64 individual PIs). Similarly, most KPIs are used in one specific SPI (sum of 35 occurrences versus 33 individual KPIs). Table 2 lists the individual KPIs.

\subsection{Comments to the Shipping KPI standard}

A general complaint that is regularly heard from prospective users of the standard is that they do not trust the data entered by some ship management companies and that benchmarks will be skewed by too positive reports from these managers. This does probably correspond to the mistrust between owners and ship managers referred to in Section 3. This is a valid point as there is no certification or review mechanism in place today that can guarantee validity. However, one can argue that the large number of ships in the database would at least reduce the potential problem and may also make it possible to detect suspicious data from certain ships managers.

A related problem has been observed during implementation of the reporting regime in a company (Nesheim 2013). Poor data quality may result from lack of understanding of the standard or to organizational factors such as fear that reported values can cause

Table 1 Overview of shipping performance indexes

\begin{tabular}{|c|c|c|c|}
\hline SPI & General description & KPIs & PIs \\
\hline SPI001 environmental performance & $\begin{array}{l}\text { Ability to avoid spills and other forms } \\
\text { of pollution that impact the environment, } \\
\text { caused by the vessel operations. }\end{array}$ & 4 & 6 \\
\hline SPI002 health and safety performance & $\begin{array}{l}\text { Ability to effectively manage the health } \\
\text { and safety of the personnel on board. }\end{array}$ & 5 & 14 \\
\hline SPI003 HR management performance & $\begin{array}{l}\text { Ability to employ, retain, and develop } \\
\text { personnel with the required competences. }\end{array}$ & 7 & 20 \\
\hline SPI004 navigational safety performance & $\begin{array}{l}\text { Safe navigation and absence of } \\
\text { navigational deficiencies. }\end{array}$ & 2 & 5 \\
\hline SPI005 operational performance & $\begin{array}{l}\text { Operational efficiency of the vessel } \\
\text { including passenger care, safe and efficient } \\
\text { cargo handling, vessel availability, and } \\
\text { budget management. }\end{array}$ & 8 & 17 \\
\hline SPI006 security performance & Ability to manage vessel security. & 2 & 4 \\
\hline SPI007 technical performance & Maintenance and reliability of technical systems. & 2 & 2 \\
\hline SPI008 other & $\begin{array}{l}\text { Miscellaneous, related to port state control, } \\
\text { fire and explosion, and emissions to air. }\end{array}$ & 5 & 10 \\
\hline
\end{tabular}


Table 2 General mapping from SHIPMAN to Shipping KPI

SHIPMAN Shipping KPI

4. Technical management

5. Crew management and crew insurances

6. Commercial management

7. Insurance
Ballast water management; failure of critical equipment and systems; fire and explosions; flawless PSC performance; PSC deficiency ratio; PSC detention; vessel availability; navigational incidents; cargo-related incidents; releases of substances as defined by MARPOL Annex 1-6; contained spills; environmental deficiencies; navigational deficiencies; operational deficiencies; security deficiencies; passenger injury ratio; vetting deficiencies; CO2 efficiency; NOx efficiency; SOx efficiency; conditions of class; dry-docking planning performance

Lost time injury frequency; lost time sickness frequency; crew planning; officer experience rate; officer retention rate; health and safety deficiencies; HR deficiencies; training days per officer; cadets per ship; crew disciplinary frequency

Budget performance

$\mathrm{n} / \mathrm{a}$

consequences for departments or individuals. The quality of the data reported is very dependent on a good implementation process in the organization.

Another criticism against the Shipping KPI standard is that some of the KPIs in an SPI group have limited relevance and that the weighting of KPIs into the high-level SPIs is not always logical. The latter issue was investigated by Duru et al. (2013) where a quantitative approach to mapping KPIs to stakeholders' interests was used. The study showed a high variability in some SPI categories with regard to the perceived importance of the KPIs in the group. However, for $\mathrm{PbC}$, this does not matter as one will normally use KPIs rather than SPIs in performance judgements as there is too high granularity on the SPI level.

Interestingly enough, the study by Duru et al. shows a much higher weight on "cheap service" (0.27) and "business network and cost efficiency" (0.26) than, e.g., "ensuring the good condition of hull" (0.18). Although only 12 operators participated in the study, the result is quite different from the conclusions from other studies referred to in Section 3. The investigation also showed that the two most important KPIs, from the users' perspective, were the "flawless port state control performance" and the "budget performance." The budget performance is obviously relevant for operational costs and a port state detention of the ship can be very costly in terms of off hire.

Finally, there have been some discussions on the relevance and/or definitions of some KPIs. As will be discussed in the next subsection, the emission efficiency indicators were not used in the $\mathrm{PbC}$ scheme as the values are dependent on the cargo volume transported, over which the manager normally has no control. This could also be construed as an argument that the indexes maybe should be defined differently so that the manager's contribution to performance was made clearer. Another similar comment is that there may be correlations between some KPIs that reduce their value as stand-alone indicators. This will be discussed in Section 6.1.

Further research is needed to investigate these problems and provide more information about actual data reliability. 


\subsection{Mapping Shipping KPI to SHIPMAN clauses}

By comparing SHIPMAN clauses in "Section 2 Services" with the Shipping KPI standard, indicators were sorted into groups that can be used to measure performance in three of the four areas listed in Table 2. This includes all 33 Shipping KPIs.

The mapping does not include performance indicators for all subclauses of SHIPMAN but provides a fairly good coverage of the most important areas. Some of the indicators were not used in the study as they did not satisfy all requirements listed in Section 6.1. The omitted KPIs are typeset in italics in the table.

\section{Designing a PbC for ship management based on shipping KPI}

\subsection{Using KPIs in an incentive scheme}

A PbC could be designed by mapping each KPI used in the performance measurement to some monetary value and then aggregate the net bonus or penalty. However, this principle requires a general translation of performance into monetary value, which is difficult for most KPIs. Looking at the Shipping KPIs listed in Table 2, the only KPI that easily maps to monetary value is the budget performance.

Section 3 indicates that ship owners are less concerned by management costs than other factors. However, this does not mean that the operational costs and the budget are of similarly low interest. The management fee is typically only on the order of $10 \%$ of the overall operational costs for a ship (Fig. 1), and with today's low charter rates, the operational cost and the budget performance are substantial parts of the operational economics for the owner. Also, the manager should normally have a good possibility to influence the budget performance as most cost factors are under the manager's control. The budget performance is an easily calculated number that is known to both parties. Connecting the budget performance directly to bonus payments represents a budget-linear compensation (Fisher et al. 2003).

However, budget-linear compensation does not mean that risks become linearly distributed. An obvious case here is that the manager delays necessary repairs to keep the total costs below budget. This may cause a breakdown causing a costly off hire for the owner, but which does not impact the operating costs and budget performance, until the repair is performed. This may indicate that certain budgetary costs, typically repairs, should be kept out of the budget performance measurement.

There is another potential problem of using budget performance as main factor for bonus payment in that it will encourage the manager to try to increase the budget as much as possible during contract negotiations.

To avoid that the focus on budget performance negatively impacts other performance categories, a number of KPIs were selected to provide quality control. This category consists of 21 KPIs selected from the 32 remaining KPIs. The selection was 
done by excluding from the list the KPIs falling into one or more of the following categories:

- Irrelevant for ship type (e.g., passenger-related KPIs for a cargo ship).

- The ship manager only has limited possibility to control the KPI (e.g., emission efficiency, as Shipping KPI measures these relative to transported tonnage, over which the manager has little control).

- Statistically rare (e.g., fire and explosion).

- KPI with insufficient statistical data in the Shipping KPI database at the time of the exercise (e.g., flawless port state control performance).

In the original study, some KPIs related to officer training and retention were omitted. The rationale for this was that these KPIs were mainly fleet related and that for a ship-based contract, it may not be useful to include quality indicators that cannot be linked directly to the manager's performance for that particular ship. However, as officer quality is closely linked to quality of operations, this may be decided otherwise in a real case.

It may also be argued that some of the quality KPIs used in the first study were correlated. This may apply, e.g., to the port state inspection indicators as well as to some crew management indicators. In the original study, there was not enough data available to see if such correlations existed, but this can probably be checked when more data is reported into the database. Correlation will lead to increased sensitivity in attributing bonus or penalty based on those groups of indicators.

Another obvious problem is that linking incentive schemes to indicators that are reported by the managers may lead to underreporting of "near misses." This has been documented for certain safety indicators for mine workers in Australia (Shaw et al. 2007). This is to some degree compensated for by independent assessments, e.g., from class and port state control, but the owner should still consider if some of these indicators are too important for good internal reporting to be used in an incentive scheme. This could, e.g., apply to health and safety deficiencies or HR deficiencies.

\subsection{The specific incentive scheme}

The study suggests calculating monetary reward from the budget performance and using a selection of the rest of the KPIs to define conditions for reward attribution. The principle is illustrated in Fig. 3. A positive deviation from budget (actual $<$ budgeted costs) leads to a potential bonus for the ship manager, whereas a negative deviation (actual $>$ budgeted costs) will result in a penalty. Before attributing the bonus, a quality control is effectuated, in order to ensure that the focus on operational costs does not affect negatively the quality of the other ship management operations. This is done by monitoring a set of qualityrelated KPIs and defining a minimum target level as a condition to attribute the bonus. In this case, each quality KPI is assigned a minimum target level, and the decision to grant the bonus is based on the percentage of quality KPIs meeting or exceeding their target values. In this scheme, the potential penalty (if the budget is not met) will be inflicted regardless of whether the KPI target values are met. 


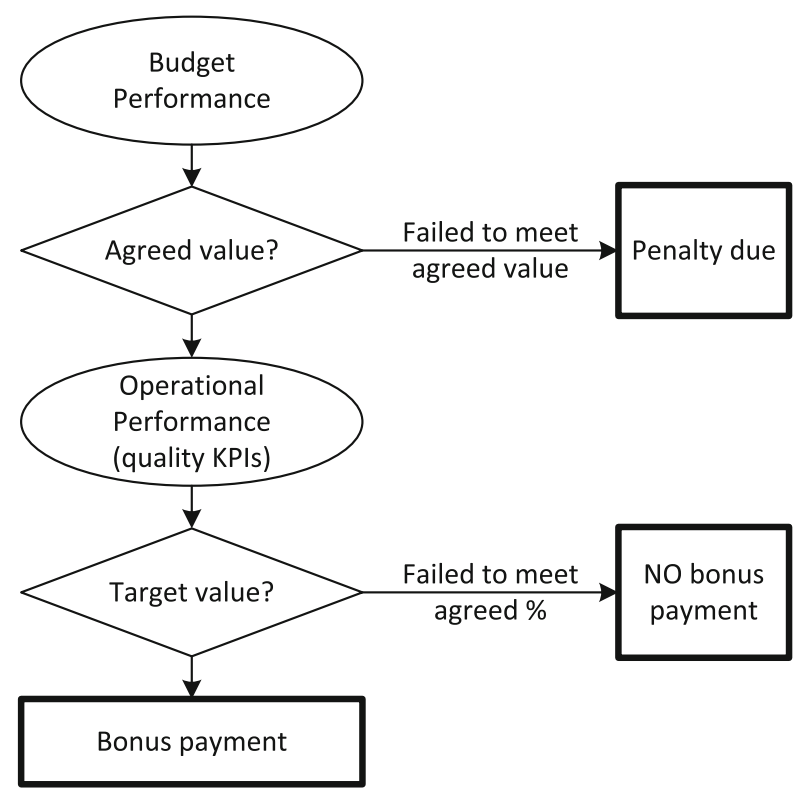

Fig. 3 Incentive scheme based on one KPI for calculating bonus/penalty and a set of other KPIs for quality control

A simple way to calculate bonus or penalty is to add or subtract a share of the ship management fee corresponding to the percentage of the budget deviation: An actual operational cost $5 \%$ higher than budget will then lead to $5 \%$ of the agreed management fee being subtracted from the actual payment. To avoid abuses and to safeguard the agent, a maximum share of the management fee at risk can be set to, e.g., $25 \%$. This ensures that the ship owner and ship manager have the same but limited monetary stake at risk.

As the size of the budget typically is 10 times the management fee, it may also make sense to have a higher multiplication factor between budget savings and increase in fee to provide a stronger incentive for ship managers through a more equal share of actual gains. This is to some degree backed up by Section 3, where studies show that owners are in general less concerned by management costs than by quality. This may, however, make most sense when the budget savings are relatively small. In the example in Table 4, the budget savings are on the order of US\$100,000 which also gives the manager a substantial bonus. Budget savings on the order of US\$10,000 are still significant for the owner, but less than $1 \%$ of the management fee may not be that important for the manager. One may require a stronger incentive to realize the gains in such cases. However, more researches are required to give an answer to this question.

In the scheme discussed here, one may also want to include a lower risk for penalties than for a bonus, e.g., by setting a lower multiplication factor for penalty than for bonus. An argument for this is that the risks inherent in this simple scheme may be much higher for the manager than the owner: The management fee is the full payment to the manager, including all overheads and profits, while operational cost for the ship is only part of the total cash flow for the owner which typically also includes charter fees as well as capital costs and own operations. However, the ratio between the 
owner's and manager's cash flow will vary greatly over time and type of ship, so this need to be looked at case by case.

An empirical example shows that penalties may be a cause of time-consuming discussions, distracting the parties and diminishing the positive effects of $\mathrm{PbC}$ (Hollebrands 2011). This also indicates that one may consider removing the penalty altogether.

\subsection{Target values for quality indicators}

In the example used in the study, the first step was to adjust the budget expectation to a level where a certain percentage of ships reached the budgetary goal. This level was set to $110 \%$ (10\% budget overrun) to reach a level of $67 \%$ budgetary success. In general, a $10 \%$ increase in operating budget is probably excessive as this corresponds to an additional full management fee. However, during negotiation between owner and manager one could, e.g., agree to increase the budget with $5 \%$. As most ships in the study already run over budget, this may not really be an additional cost for the owner, and with the proposed incentive scheme, the manager would be very motivated to reduce costs further for common benefit to owner and manager.

Then the target values for quality indicators was first set by using "common sense" and then tried against data in the Shipping KPI database to see how many ships passed the quality KPI test. For these comparisons, reported data from 200 different ships were used. The levels as well as the percentage of KPIs on or above the target were iterated upon to ensure that the manager would reach the target in a majority of the recorded cases. The percentage of KPIs to reach the target was finally set at $90 \%$ (maximum of two out of 21 KPIs below target) to enable a bonus payment. This gives the manager a bonus payment in $64 \%$ of the cases and a penalty in $33 \%$ of cases as shown in Table 3.

Table 4 shows some examples of the resulting cost figures from the exercise. Four ships have been picked out to show how this would work in four different cases. The amounts are in US\$/year and are based on interviews with managers. They are representative for a handymax $(54,000$ DWT) bulk carrier.

The four ships illustrate four distinct outcomes:

(1.) Ship one has a slight overrun on costs and a penalty is subtracted from fee, independent of quality indicators.

Table 3 Some results from demonstration case iterations

\begin{tabular}{lllll}
\hline Budget performance (at $110 \%)$ & Better & Better & Worse & Worse \\
Quality (see below rows) & Better & Worse & Better & Worse \\
Result for manager & Bonus & Even & Penalty & Penalty \\
Quality percentile $90 \%$ KPI 19/21 & $64 \%$ & $3 \%$ & $28 \%$ & $5 \%$ \\
Quality percentile 95\% KPI 20/21 & $58 \%$ & $9 \%$ & $22 \%$ & $11 \%$ \\
Quality percentile 100\% KPI 21/21 & $40 \%$ & $27 \%$ & $12 \%$ & $21 \%$ \\
\hline
\end{tabular}


Table 4 Demonstration cases and outcomes (US\$/year)

\begin{tabular}{llllll}
\hline & & Ship 1 & Ship 2 & Ship 3 & Ship 4 \\
\hline \multirow{2}{*}{ For the ship owner } & Running costs budget & $1,365,830$ & $1,365,830$ & $1,365,830$ & $1,365,830$ \\
& Budget performance & 1.02 & 0.98 & 0.93 & 1.16 \\
& Actual running costs & $1,393,147$ & $1,338,513$ & $1,270,222$ & $1,584,363$ \\
& Additional costs/savings & $-27,317$ & 27,317 & 95,608 & $-218,533$ \\
For the ship manager & Management fee & 143,445 & 143,445 & 143,445 & 143,445 \\
& Calculated bonus/penalty & $-2,869$ & 2,869 & 10,041 & $-22,951$ \\
& Percentage of quality KPIs & 95 & 76 & 100 & 86 \\
& Amount payable to manager & 140,576 & 143,445 & 153,486 & 120,494 \\
& Actual bonus/penalty & $-2,869$ & 0 & 10,041 & $-22,951$ \\
\hline
\end{tabular}

(2.) Ship two is lower on costs than budget, but as less than $90 \%$ of quality KPI target values are met, no bonus is paid.

(3.) Ship three has a better budgetary performance and more than $90 \%$ of quality KPI target values achieved and a bonus is paid.

(4.) Ship four has a significant overrun on costs and a correspondingly higher penalty is subtracted from fee, independent of quality indicators.

The valuation assumes that the ship owner reimburses the actual running costs to the ship manager regardless of whether these are above, equal to, or below budget. The limit of $25 \%$ bonus or penalty does not apply in any of the examples shown here.

\section{Discussion}

The paper presents solutions to the main challenges related to $\mathrm{PbC}$. The problem of allocative efficiency has been addressed by using both a direct financial indicator for calculation of bonus and penalty as well as a set of quality controlling indicators to determine when bonus is paid. As was discussed in Section 3, the operating budget is a significant cost factor for the owner, and it is an excellent trade-off if the actual operating costs are reduced, even though the management fee goes up somewhat. The quality indicators are already established by the management companies through the Shipping KPI standard. Determining threshold values and percentages through analysis of actual data in the Shipping KPI database ensures that both principal and agent have a good understanding of the implications of the agreed levels. The wide range of functional areas covered by the indicators should further help to reduce the allocative efficiency problem.

While allocative efficiency usually is discussed in the context of multiple tasks, it should be pointed out that there is also a temporal/spatial perspective to this. If one ship gets a number of deficiencies early in the year so that quality attributes cannot be satisfied, the manager may elect to ignore this ship for the rest of the year and put more attention on the ships that are still in the clear. This may, e.g., be catered for by creating 
contracts for the whole fleet and look at the aggregated results rather than the individual. However, this issue has not been investigated.

As mentioned in Section 6.1, there are parts of the operating budget, e.g., repairs, which may incite the manager to delay activities to the degree that it results in off hire for the owner. The budget performance indicator could take this into account by removing such parts of the budget from the performance calculations.

Information asymmetry has been addressed by using the Shipping KPI standard which is generally recognized as a consistent set of performance measurement indicators. With reports from more than 2,000 ships today, the statistical significance should be satisfactory, and by using the outlined procedure for establishing performance thresholds, the resulting levels and percentages should be fully transparent for both agent and principal. The set of indicators are well defined and relatively easy to verify by the ship owner or by third parties, if this should be needed.

The complexity of setting up a $\mathrm{PbC}$ is greatly simplified by providing a standard set of indicators as well as a readily available database for calculation of benchmark values. The principles discussed in this paper are easy to apply and easy to verify by both parties. Using the database to determine levels for payment of bonus or penalties during contract negotiation is also a method that is completely transparent and easily verifiable by the parties.

\section{Conclusion}

This paper has gone through one example of how a performance-based contract $(\mathrm{PbC})$ between ship owners and ship managers can be designed on the basis of the Shipping KPI standard and database. The example represents a relatively simple exercise, but the simplicity avoids unforeseen side effects; it helps to ensure transparency and information symmetry, and it reduces administrative overhead by minimizing hidden pitfalls both for agent and principal.

The example is aimed at assessing the adequacy of the Shipping KPI standard as a basis for an incentive scheme applied to a case of multitask principal/agent relationship. The example has demonstrated how the $\mathrm{PbC}$ would work and what the results would be, using historical data from the Shipping KPI database. Although details of the design may be adjusted, the authors believe that the demonstrated principles address many of the concerns that have been voiced about $\mathrm{PbC}$.

The authors believe that the Shipping KPI standard could be a good basis for establishing performance-based contracts between ship managers and owners. This requires that owners and managers that are willing to invest some effort into investigating the practical effects of such a contract over sufficiently long period. Some issues that need to be investigated further are the following:

- It would be useful to revisit the definitions of the Shipping KPI indicators and see how they match up to the requirements of $\mathrm{PbC}$. Some specific issues were reported in Section 5.3.

- There is a need to assess the data reliability in the Shipping KPI repository.

- One may want to look into contract forms covering more than one ship to avoid the "temporal/spatial allocative efficiency" problem. 
- It is necessary to look how to handle parts of the operating budget that may represent high risks for the owner, e.g., unscheduled repairs.

- Likewise, more research may be needed in reaching a good balance between risk for owner and manager. The most simplistic scheme may transfer too much risk to manager.

- It would be interesting to extend $\mathrm{PbC}$ to the tri-dimensional agency, reflecting relationships between ship owner, ship manager, and charterer.

Although more work is needed, it is hoped that this paper can contribute to a better and more effective cooperation between owners and managers.

Acknowledgments The authors extend thanks to the reviewers which provided many suggestions that have very much improved the paper from the first version. Thanks are also extended to a number of ship manager companies that provided own business data for the study and to InterManager for the use of the Shipping KPI database.

\section{References}

Al-Subhi Al-Harbi KM (1998) Sharing fractions in cost-plus-incentive-fee contracts. Int J Proj Manag 16(2): 73-80

BIMCO (2009) Baltic and International Maritime Council, SHIPMAN 2009, Standard Ship management contract (Sample). Available from BIMCO (www.bimco.org)

Duru O et al (2013) Shipping performance assessment and the role of key performance indicators (KPIs): quality function deployment for transforming shipowner's expectation. Available at SSRN 2195984

Fearnley N, Bekken JT, Norheim B (2004) Optimal performance-base subsidies in Norwegian intercity rail transport. Int J Transp Manag 2(2004):29-38

Feltham GA, Xie J (1994) Performance measure congruity and diversity in multi-task principal/agent relations. Account Rev 69(3):429-453

Fisher JG, Peffer SA, Sprinkle GB (2003) Budget-based contracts, budget levels, and group performance. J Manag Account Res 15:51-74

Gibbs M, Merchant KA, Van der Stede WA, Vargus ME (2004) Performance measure properties and incentives, IZA Discussion Paper No. 1356, October 2004

Hollebrands J (2011) Performance-based contracting: a new tool in ship management?, Dissertation, Middlesex University

Holmstrom B, Milgrom P (1991) Multitask principal-agent analyses: incentive contracts, asset ownership, and job design. J Law Econ Org 7:24-52

Homburg C, Stebel P (2009) Determinants of contract terms for professional services. Manag Account Res 20: $129-145$

Hooper L (2008) Paying for performance: uncertainty, asymmetric information and the payment model. Res Transp Econ 22:157-163

Kerr S (1975) On the folly of rewarding a, while hoping for b. Acad Manag J 18(4):769-783

McCall JJ (1970) The simple economics of incentive contracting. Am Econ Rev 60(5):837-846

Michael F (1957) The measurement of productive efficiency. J R Stat Soc Ser A (Gen) 120(3):253-281

Mitroussi K (2004) The ship owners' stance on third party ship management: an empirical study. Marit Policy Manag: Flagship J Int Shipp Port Res 31(1):31-45

Nesheim DA (2013) MOPS WP1 Implementation of Shipping KPI reporting regime, MARINTEK Unrestricted Report, PNO 28016610, 2013-07-13, Version 1.3

Norbeck JA, Nesheim DA, Rialland A, Rødseth ØJ (2011) Flagship deliverable D-A1.5: Demonstration of KPIs used in performance based contracts, 2011-05-31

Olmos MF, Martinez JR (2010) The quality-quantity trade-off in the principal-agent framework. Agric Econ Rev 11(1):57-68

Panayides PM, Cullinane KPB (2002) The vertical disintegration of ship management: choice criteria for third party selection and evaluation. Marit Policy Manag: Flagship J Int Shipp Port Res 29:1 
Rajan MV, Reichelstein SJ (2009) Objective versus subjective indicators of managerial performance. Account Rev 84(1):209-237

Shaw A et al (2007) Digging deeper, Independent Consultant Report by Shaw Idea, Commissioned by NSW Mine Safety Advisory Council, November 2007, ISBN: 9780734718839

Shipping KPI (2012) Official web site on https:/www.shipping-kpi.org/

Woods A (2012) Subjective adjustments to objective performance measures: the influence of prior performance. Orig Res Artic Account Organ Soc 37(6):403-425

Zhao RR (2008) All-or-nothing monitoring. Am Econ Rev 98(4):1619-1628 